\title{
A novel active equalization topology for series- connected lithium-ion battery packs
}

\author{
Xiaofeng Ding, Member, IEEE, Donghuai Zhang, Jiawei Cheng, Binbin Wang, \\ Yameng Chai, Zhihui Zhao, Rui Xiong, Senior Member, IEEE, and Partrick Chi Kwong \\ Luk, Senior Member, IEEE
}

\begin{abstract}
A novel non-dissipative two-stage equalization circuit topology based on the traditional Buck-Boost circuit is proposed to achieve balancing of series-connected lithium-ion battery packs with higher efficiency and less cost, considering the background on international energy issues and the development trend of battery balancing. The proposed topology achieves high efficient balancing of lithium-ion battery packs without adding additional devices. Detailed illustration of the presented topology, the operation principles and control approaches are described with visualized figures in this paper. Then, under the condition of accurate modeling of the lithium-ion battery, relying on the experimental data, the simulation block is built based on MATLAB. Furthermore, the prototype of the proposed topology was designed and manufactured. The effectiveness of the proposed topology is verified by both the simulation and experiment.
\end{abstract}

Index Terms-- Active equalization, Buck-Boost topology, Lithium-ion battery model, Balancing time

\section{INTRODUCTION}

Due to the shortage of oil supply and awareness of environment issues, it has become a global consensus to accelerate the development and popularization of electric vehicles (EVs) [1]. And the power battery is the bottleneck problem of EVs. Lithium-ion batteries are primary choices for EVs, owing to their outstanding performances, such as high energy density, high charging and discharging velocity, long service life and safety.

Limited to the voltage and capacity of the lithium battery monomer, hundreds or thousands of battery cells must be connected in series and in parallel to form a battery pack, so as to provide the electric vehicle sufficient power and energy to meet the requirements of acceleration, climbing and the mileage [2]. However, the consistency of the battery pack will deteriorate with the increasing number of charging and discharging due to the objective inconsistency between the
TABLE I

Comparison of typical equalization circuit topologies

\begin{tabular}{|c|c|c|c|c|c|c|}
\hline Name & $\begin{array}{c}\text { Equilibrium } \\
\text { speed }\end{array}$ & $\begin{array}{c}\text { Control } \\
\text { difficulty }\end{array}$ & Cost & $\begin{array}{c}\text { Implementation } \\
\text { complexity }\end{array}$ & Volume & $\begin{array}{c}\text { Energy } \\
\text { efficiency }\end{array}$ \\
\hline $\begin{array}{l}\text { Switched } \\
\text { capacitor }\end{array}$ & Slow & Difficult & Low & Medium & Small & Higher \\
\hline Cuk & Fast & Difficult & High & Complicated & Medium & High \\
\hline Transformer & Fast & Difficult & High & Complicated & Huge & Low \\
\hline Buck-Boost & Fast & Difficult & Medium & Simple & Medium & High \\
\hline
\end{tabular}

battery cells. The deterioration could decrease the actual accessible energy and what's even worse, shorten the life cycle of the battery pack [3]. Therefore, it is necessary and crucial to carry out comprehensive, high-efficient and refined management on the power battery, utilizing the battery management system (BMS).

Battery balancing is the key issue as well as where the difficulty lies to the BMS. The main idea of battery balancing is to use the power electronic converter to transfer or consume the energy of the battery to achieve the purpose of balance. Generally, the equalization circuits of lithium-ion batteries are divided into dissipative ones and non-dissipative ones, which can also be called passive equalization and active equalization, respectively [4]. Passive balancing method based on resistor is simple, reliable and easy to implement, which is still the most widely used method of equalization nowadays, in spite of several obvious shortcomings, such as the problem of energy waste, time-consuming process and heat dissipation [5].

In contrast, the active equalization is more in line with the development trend of energy-saving and high efficiency. According to the different power electronic devices used, the active equalization topology can be categorized into four basic types, namely the topologies based on capacitors, inductors, capacitors and inductors, and transformers [6].

The topology based on capacitors is utilizing the switch devices and the capacitance to achieve equalization control [7]. The control method is simple, but when the voltage difference between the battery cells is small, the equalization speed is

Rui Xiong is the corresponding author (e-mail: riuxiong@bit.edu.cn). 


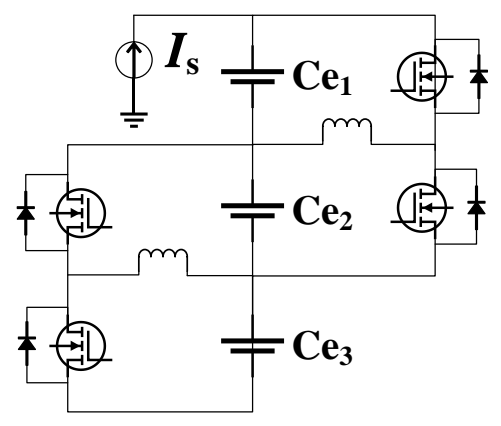

Fig.1 Buck-Boost topology.

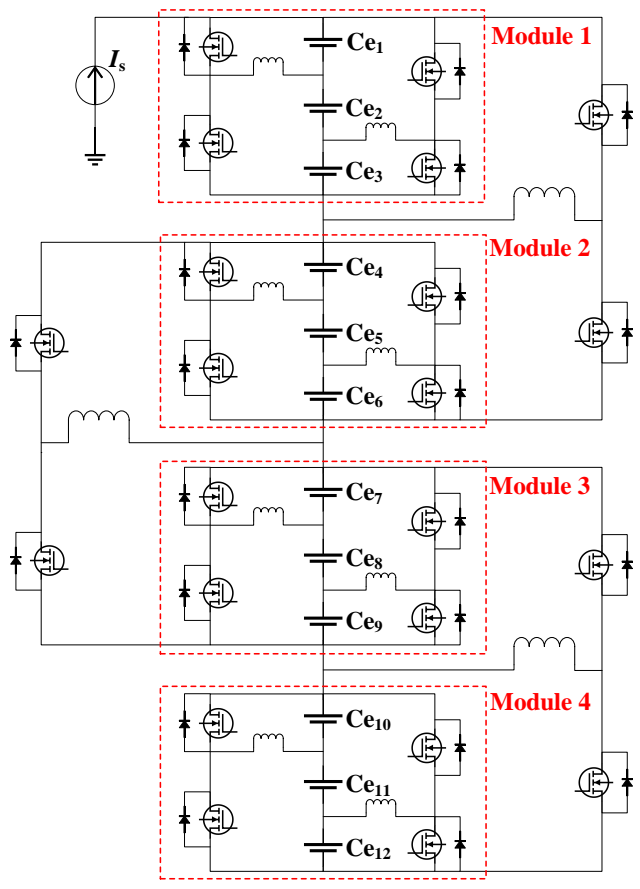

Fig. 2 The proposed two-stage equalization circuit.

very slow. The classic inductor-based topology is a BuckBoost equalization circuit [8-9]. The structure is simple, and the number of components is small. In addition, the balancing speed is fast and the precision is high. The other topology based on capacitance and inductance is a Cuk equalization circuit [10-11]. The speed is fast, while the structure is more complicated. The transformer equalization circuit is based on a multi-winding transformer [12-14]. The topology is complex and costly. According to the characteristics of the above four equalization circuits, a simple arrangement is made and shown in Table I.

Comprehensive comparing with the other three topologies, the Buck-Boost circuit is a good choice. The equalization topology of the inductor-based Buck-Boost circuit is shown in Fig. 1, whose equalization unit consists of one energy storage inductor, two Schottky diodes and two metal-oxide semiconductor field effect transistor (MOSFET) switches [15]. The adjacent two cells share one equalization unit and each equalization unit has exactly the same structure. The energy

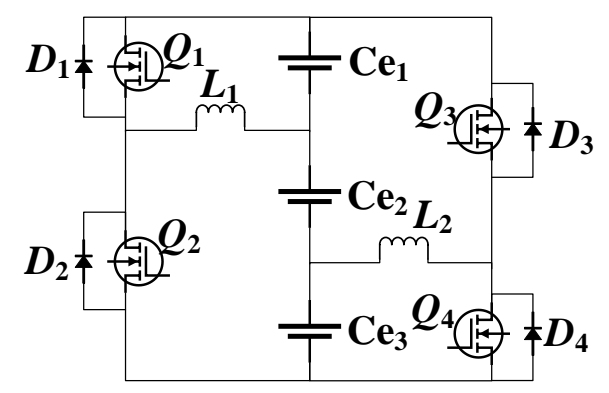

Fig. 3 The elementary equalization module

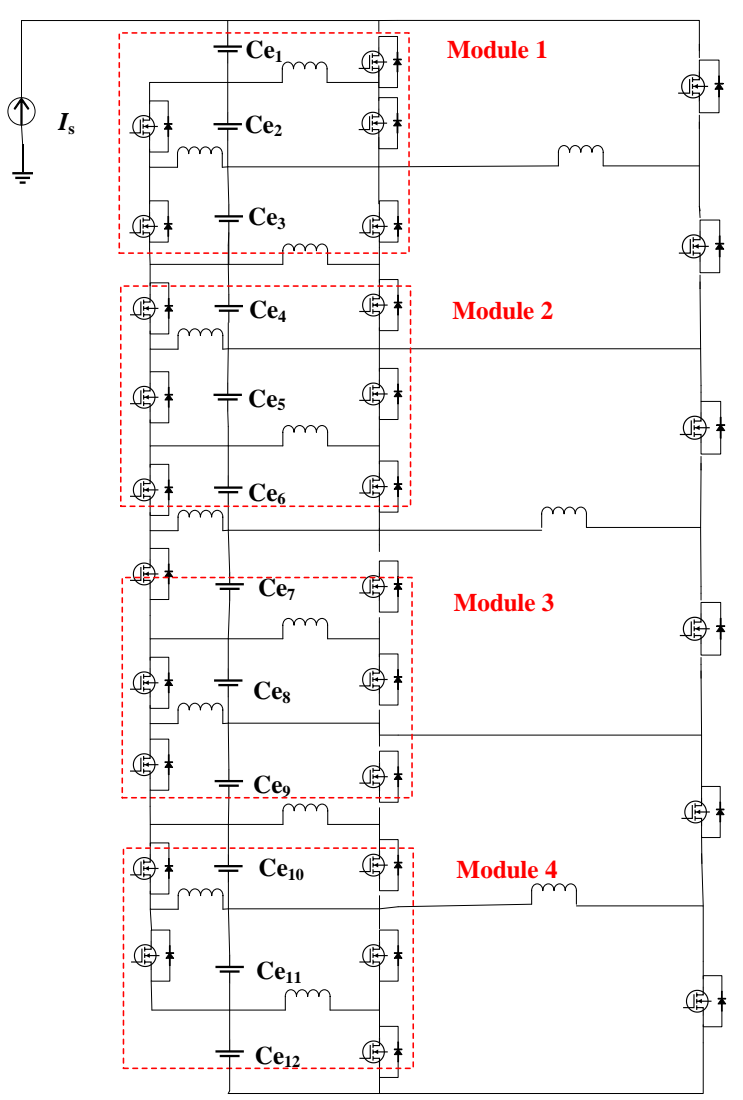

Fig. 4 The traditional two-stage equalization circuit.

can flow in either direction from one cell to the adjacent one in an efficient and precise way. Paper [16] proposed an active equalizer for Li-ion battery pack in EVs based on cell-to-packto-cell topology. The proposed equalizer consists of a switch array and a single-ended forward bidirectional DC-DC converter, which is efficient and reliable. However, the circuit structure and control algorithm are complicated. In paper [17], a battery equalizer based on bipolar CCM buck-boost is proposed to improve the conversion efficiency. However, the equalizer is introduced into the soft switching technology to reduce the switching, while the speed of battery equalization is not much improved.

In order to further improve the balancing speed without 


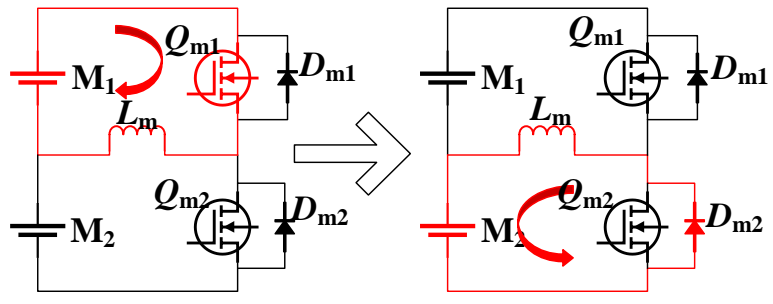

(a)

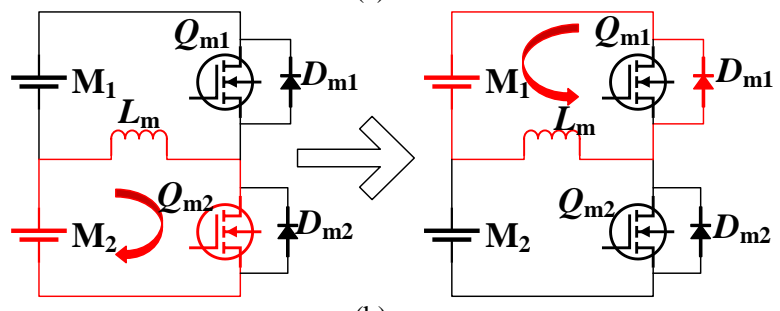

(b)

Fig. 5 Operational principle of the second stage. (a) $Q_{\mathrm{m} 1}$ operating; (b) $Q_{\mathrm{m} 2}$ operating.

adding additional devices, this paper proposed an optimized active equalization circuit topology based on the classical Buck-Boost converter topology [18]. Firstly, the proposed topology is described in detail in section II. Section III presents the specific calculations of the parameters of the equalization topology. In Section IV, the accurate modeling of the specific lithium-ion battery and the equalization topology simulation block is accomplished. Then, the prototype of the proposed topology was designed and manufactured. And the experiments based on this prototype was implemented and the results are shown in section V. Finally, Section VI makes the conclusion.

\section{PROPOSED ACTIVE EQUALIZATION TOPOLOGY}

\section{A. Circuit descriptions}

A novel two-stage equalization circuit is proposed, which is based on the Buck-Boost converter circuit and takes power inductors to deliver energy among battery cells. Taking 12 battery cells in series for example, this two-stage topology, shown in Fig. 2, is composed of 11 inductors as well as 22 MOSFET switches with the same number of diodes. It takes three battery cells to form an elementary equalization unit as the first stage, shown in Fig. 3, which consists of two storage inductors $\left(L_{1}\right.$ and $\left.L_{2}\right)$ and four power MOSFET switches $\left(Q_{1}\right.$, $Q_{2}, Q_{3}$ and $\left.Q_{4}\right)$ with body diodes $\left(D_{1}, D_{2}, D_{3}\right.$ and $\left.D_{4}\right)$, while the framework of the second stage circuit is the same as the basic Buck-Boost converter topology. The only variation is that the equalization modules take place of the battery cells, reflecting the holistic ideology.

Compared to the basic one-stage Buck-Boost converter topology, the proposed two-stage topology, possessing the same quantity of devices though, is supposed to accomplish

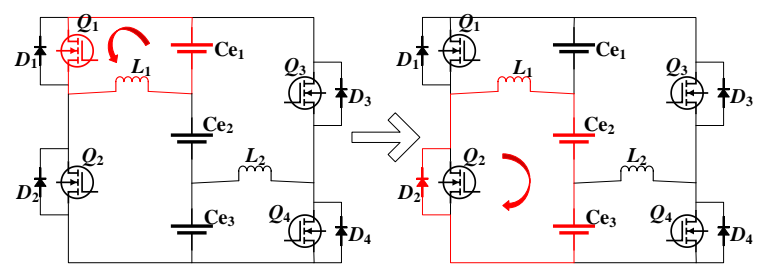

(a)

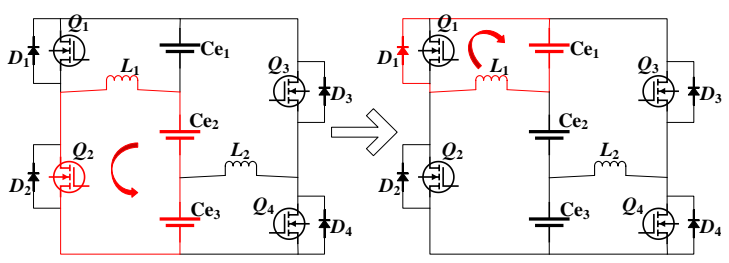

(b)

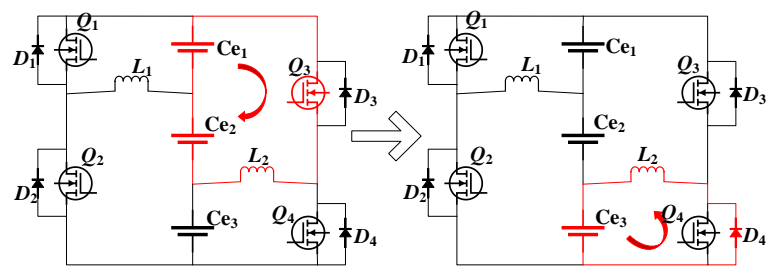

(c)

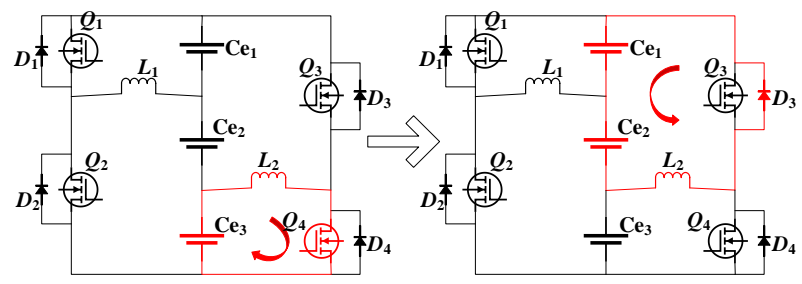

(d)

Fig. 6 Operational principle of the first stage. (a) $Q_{1}$ operating; (b) $Q_{2}$ operating; (c) $Q_{3}$ operating; (d) $Q_{4}$ operating.

the equalization within less time in theory, depending on its structural advantage. By contrast with the traditional two-stage topology with the adjacent three cells forming one equalization unit based on the Buck-Boost, which needs at least 14 inductors and 28 MOSFET switches of the same specification in total to meet the same current limit as shown in Fig.4, this proposal makes it possible to reduce the quantity of devices, so as to cut costs. These will be demonstrated by the simulation results in section IV.

\section{B. Operational principle}

The working principle of the second stage equalizing topology is exactly the same as that of the Buck-Boost circuit. On the basis of judging the state of charge (SOC) of two adjacent modules of batteries, the energy can be shifted from the higher one to the lower one through the manners of the MOSFET switches operating, shown in Fig. 5. Taking $Q_{\mathrm{m} 1}$ 


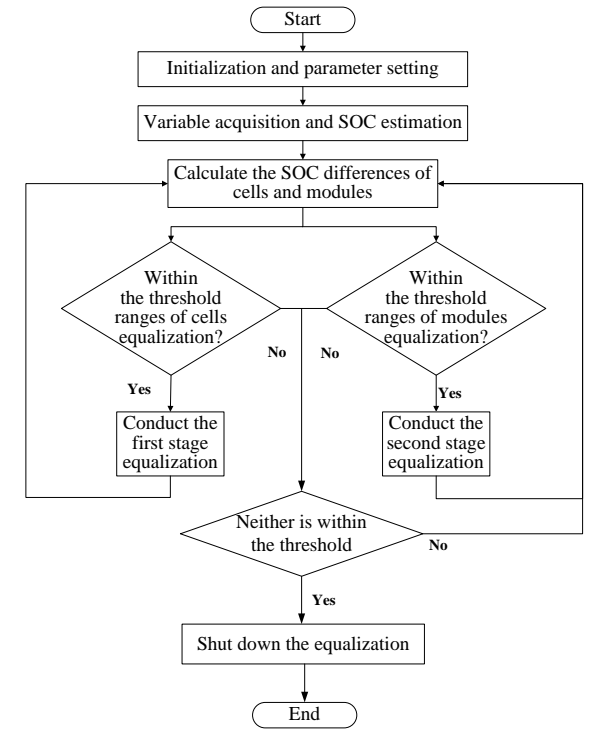

Fig.7 The flow chart of two-stage equalization control approaches.

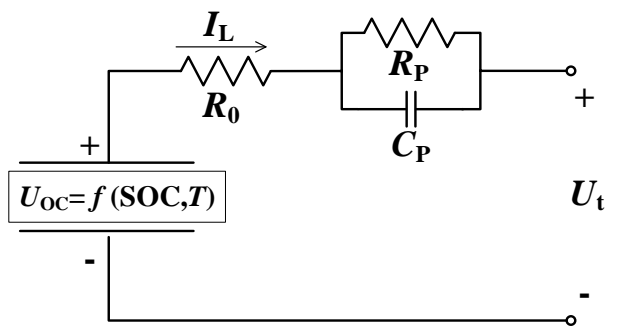

Fig. 8 The combined battery model

operating for example, as shown in Fig. 5(a), $Q_{\mathrm{m} 1}$ will be turned on when the input control signal from equalization control system reaches the high level. Then, module $\mathrm{M}_{1}$ discharges through the marked loop which consists of $\mathrm{M}_{1}, Q_{\mathrm{m} 1}$ and $L_{\mathrm{m}}$. During this period, the current increases from zero while the electric energy is converted to magnetic energy and stored in the inductor $L_{\mathrm{m}}$. After that, when the control signal turns to low voltage, resulting in $Q_{\mathrm{m} 1}$ turning off, the magnetic energy in $L_{\mathrm{m}}$ is released and reconverted into electric energy. In this period, the current decreases and module $M_{2}$ is charged. These two periods constitute one switching cycle, whose time length and duty cycle both depend on the control signal. Similarly, the energy can be transferred from $M_{2}$ to $M_{1}$ by controlling $Q_{\mathrm{m} 2}$, as shown in Fig. 5(b).

Simultaneously, the first stage works in a different way to let the energy flow among the three cells and reach the balance. Fig. 6 shows the working principle of the equalization unit during the balancing process, which is separated into four different cases according to comparison results of the SOC among the three cells, analyzed as follows. Taking $Q_{1}$ operating for example, if the $\mathrm{SOC}$ of $\mathrm{Ce}_{1}$ is higher than the average of the three cells SOC, the input control signal of $Q_{1}$ is set to a high level, then $Q_{1}$ turns on, $\mathrm{Ce}_{1}$ discharges, and $L_{1}$
TABLE II

EQUALIZATION TOPOLOGY PARAMETERS

Parameter Value

$\begin{array}{cc}T_{\mathrm{S}} / \mathrm{s} & 0.000 \\ L_{\mathrm{m}} / \mu \mathrm{H} & 100\end{array}$

$L / \mu \mathrm{H} \quad 50$

$\mathrm{D}_{\mathrm{M}} \quad 0.4$

$\mathrm{D}_{14} \quad 0.4$

$\mathrm{D}_{23} \quad 0.2$

stores energy. The input control signal of $Q_{1}$ is set to a low level and $Q_{1}$ is turned off when the SOC is equal to the average SOC. The $Q_{2}, Q_{3}$, and $Q_{4}$ work under the same logic. The loop consisting of $\mathrm{Ce}_{1}, Q_{1}, L_{1}$ is formed while the red arrow in Fig. 5(a) represents the current direction. During this period, the current increases gradually from zero while the electric energy of $\mathrm{Ce}_{1}$ is converted to magnetic energy, stored in the inductor $L_{1}$. The voltage magnitude of $\mathrm{Ce}_{1}$ and the conduction time of $Q_{1}$ determine the current increment. Secondly, when $Q_{1}$ is turned off, and then the loop of $L_{1}, \mathrm{Ce}_{2}, \mathrm{Ce}_{3}, D_{2}$ is formed, the current decreases gradually back to zero while the magnetic energy in $L_{1}$ is released and reconverted to electric energy. In general, the discharging of $\mathrm{Ce}_{1}$ and the charging of $\mathrm{Ce}_{2}$ and $\mathrm{Ce}_{3}$ are accomplished during the process. When confronted with the other cases, the operation process is similar, no more tautology here.

\section{Control approach}

Since the working principle of the second stage is the same with the Buck-Boost topology, the control method is also the same. On the basis of the acquirement of the average SOC value of each module, the simple control approach can be formulated to get the modules equalized.

Emphasis is placed on the formulation of the control method for the first-stage equalization module. Since one module is composed of three battery cells, the judgment condition is no longer the comparison of adjacent cells, but the SOC of each cell compared with the average value of the three. According to the difference between each cell's SOC and the average value, $Q_{1}$ to $Q_{4}$ can be operated separately, so as to reach the consistency as fast as possible. Determined by the circuit structure itself, only two of the four MOSFET switches allow simultaneous operation. In order to prevent some analogous expectable malfunctions or "over-equalization" happening, the operating conditions of the MOSFET switches must be strictly limited. A certain threshold must be given and a corresponding control strategy ought to be designed. The threshold is set according to the accuracy required for equalization. The higher the accuracy, the smaller the threshold, and the longer the equalization time required.

Referring the concepts of mean and maximum difference in statistics, the maximum difference between the SOC value and the mean value of the three cells is used as an indicator of the inconsistency evaluation. The system sensitivity is adjusted by changing the threshold of the maximum difference. The overall operation principles are to perform first-stage equalization on the basis of second-stage equalization, and 


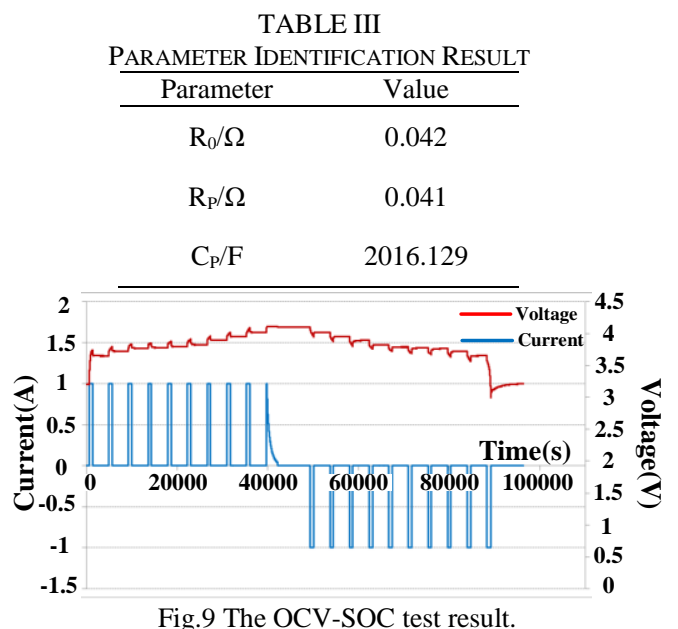

Fig.9 The OCV-SOC test result.

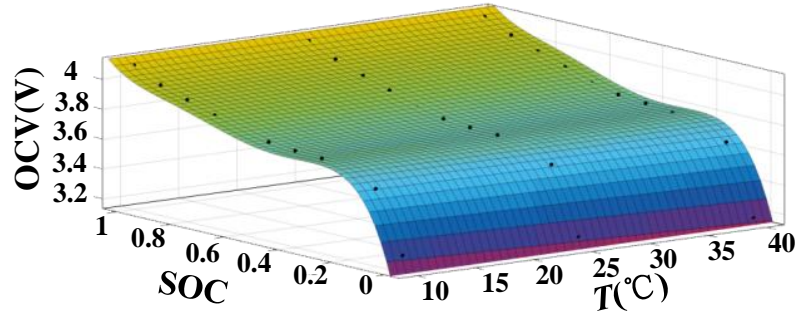

Fig.10 The polynomial fitting result.

both can be simultaneously performed to shorten the time. However, for the proposed two-stage equalization circuit, the second-stage equalization of the topology needs to be completed before the end of first-stage equalization. If the second-stage equalization is still in progress while the firststage equalization is stopped, the local equilibrium state may change, causing the inconsistency to re-expand. For the three different conditions of standing, charging and discharging of the battery pack, only the determination conditions of the start and end of the equalization action need to be constrained accordingly under the selected switching cycle and duty cycle.

(a) Standing and charging: The threshold of cells SOC for the second-stage equalization is set to 0.02 while the threshold of modules for the first-stage equalization is set to 0.01 .

(b) Discharging: Considering that the battery is in the discharge condition, the randomness of the current variation is very large, which tends to cause over-equilibrium, so the equilibrium threshold should be increased accordingly. The threshold is set to 0.04 in the second-stage equalization while 0.02 in the first-stage equalization.

The threshold voltage is determined by the system precision. The equilibrium strategy proposed in this paper aims to balance the SOC between the cells, while the circuit sensor measures the OCV (open circuit voltage) of the cell, the relationship between SOC and OCV is (10). The system requires the accuracy of $1 \%$. According to (10), a SOC fluctuation of $1 \%$ will result in a voltage fluctuation of $0.01 \mathrm{~V}$. The threshold voltage cannot be reduced indefinitely. The

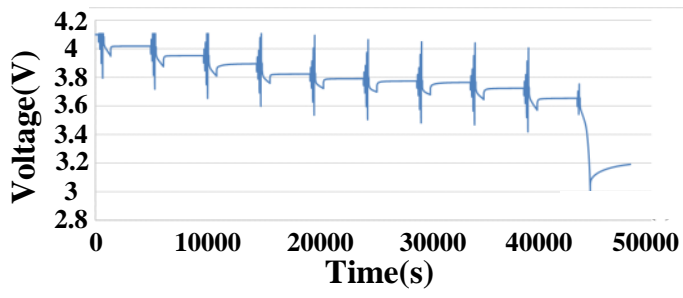

(a)

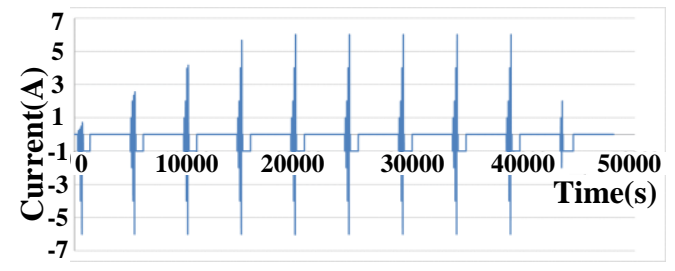

(b)

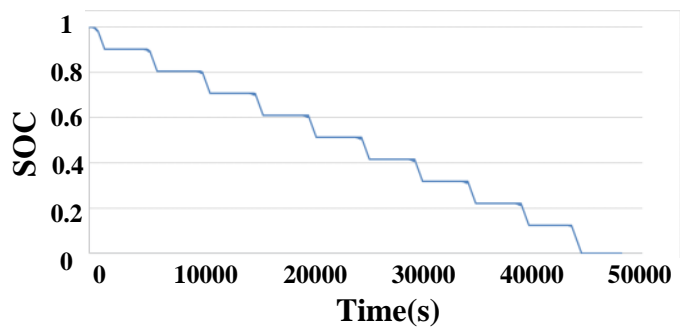

(c)

Fig.11 The HPPC test result. (a) Voltage;(b) Current; (c) SOC
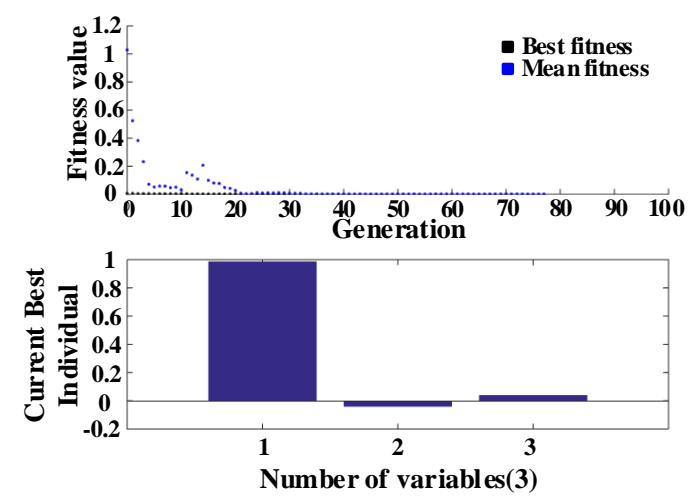

Fig.12 The parameter identification result by genetic algorithm.

sensor's measurement error is $1.2 \mathrm{mV}$, if we set the threshold to be at the order of $0.001 \mathrm{~V}$, the fluctuation of signal will lead to the repeated operation of the equilibrium circuit.

The strategy in this paper is that the SOC between the modules should be completed before cells. Therefore, the threshold voltage of the second-stage should be larger than the threshold voltage of the first-stage. Considering the accuracy requirements and the sampling capacity of the actual circuit, two significant digits are reserved. The threshold voltage of the first-stage was set to $0.01 \mathrm{v}$ and the second-stage to $0.02 \mathrm{v}$

The established overall operation principles are shown in Fig. 7, reflected in the form of the block diagram. When the 
calculated SOC difference is not within the set threshold range, the equilibrium operation is exited. In order to ensure the stability of the second-stage equalization, the first-stage and second- stage equalization are simultaneously performed in the control strategy, and the threshold is set to ensure that the second- stage is completed before the first- stage, thereby avoiding a conflict between two stages, which will cause the equilibrium to fall into an infinite loop.

\section{PARAMETER CALCULATION}

From the analysis above, the magnitude of the balancing current is related to the battery voltage, the duty cycle of the MOSFET switch as well as the inductance of the power inductor. Therefore, quantitative analysis is of great necessity to determine the parameters of the control signals and circuit components.

Referring to Fig. 6, when $Q_{1}$ is operating, the current increment is

$$
\left\{\begin{array}{l}
\Delta i_{\mathrm{L+}}=\frac{U_{1}}{L} \mathrm{D}_{14} T_{\mathrm{S}} \approx \frac{U T_{\mathrm{S}}}{L} \mathrm{D}_{14} \\
\Delta i_{\mathrm{L}-}=\frac{U_{2}+U_{3}}{L} \mathrm{D}_{14}^{\prime} T_{\mathrm{S}} \approx \frac{U T_{\mathrm{S}}}{L} 2 \mathrm{D}_{14}^{\prime}
\end{array}\right.
$$

When $Q_{4}$ is operating, the current increment is

$$
\left\{\begin{array}{l}
\Delta i_{\mathrm{L}+}=\frac{U_{3}}{L} \mathrm{D}_{14} T_{\mathrm{S}} \approx \frac{U T_{\mathrm{S}}}{L} \mathrm{D}_{14} \\
\Delta i_{\mathrm{L} \cdot}=\frac{U_{1}+U_{2}}{L} \mathrm{D}_{14}^{\prime} T_{\mathrm{S}} \approx \frac{U T_{\mathrm{S}}}{L} 2 \mathrm{D}_{14}^{\prime}
\end{array}\right.
$$

When $Q_{2}$ is operating, the current increment is

$$
\left\{\begin{array}{l}
\Delta i_{\mathrm{L}+}=\frac{U_{2}+U_{3}}{L} \mathrm{D}_{23} T_{\mathrm{S}} \approx \frac{U T_{\mathrm{S}}}{L} 2 \mathrm{D}_{23} \\
\Delta i_{\mathrm{L}-}=\frac{U_{1}}{L} \mathrm{D}_{23}^{\prime} T_{\mathrm{S}} \approx \frac{U T_{\mathrm{S}}}{L} \mathrm{D}_{23}^{\prime}
\end{array}\right.
$$

When $Q_{3}$ is operating, the current increment is

$$
\left\{\begin{array}{l}
\Delta i_{\mathrm{L}+}=\frac{U_{1}+U_{2}}{L} \mathrm{D}_{23} T_{\mathrm{S}} \approx \frac{U T_{\mathrm{S}}}{L} 2 \mathrm{D}_{23} \\
\Delta i_{\mathrm{L}-}=\frac{U_{3}}{L} \mathrm{D}_{23}^{\prime} T_{\mathrm{S}} \approx \frac{U T_{\mathrm{S}}}{L} \mathrm{D}_{23}^{\prime}
\end{array}\right.
$$

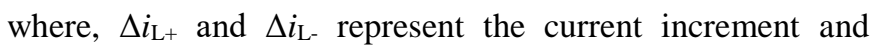
decrement, respectively. $T_{\mathrm{S}}$ is the switching period, $L$ is the inductance value, $U_{\mathrm{i}}$ is the voltage value of cell (i), $\mathrm{i}=1,2,3, U$ is the average voltage value of three cells, $\mathrm{D}_{14}$ and $\mathrm{D}_{23}$ represent the duty cycle of $Q_{1}, Q_{4}$ and $Q_{2}, Q_{3}$, separately.

In order to make the inductor current drop back to zero in each switching cycle, scilicet operating in the discontinuous current mode (DCM) [19], the range of the duty cycle can be calculated as

$$
\left\{\begin{array}{l}
D_{14} \leq 0.66 \\
D_{23} \leq 0.33
\end{array}\right.
$$

For the lithium-ion battery with a capacity of $2 \mathrm{Ah}$, it is generally necessary to control the equalizing current not to exceed $3 \mathrm{C}$, namely $6 \mathrm{~A}$. Considering $10 \mathrm{kHz}$ as the switching frequency of the MOSFET, and taking the condition into account that two MOSFET switches operating simultaneously, then $2 \Delta i_{\mathrm{L+}} \leq 6 \mathrm{~A}$.

The second-stage equalization topology, taking Fig. 5 for referring, also needs to work in the DCM. The range of the duty cycle of $Q_{\mathrm{m} 1}$ can be calculated similarly as

$$
\mathrm{D}_{\mathrm{M}} \leq 0.5
$$

Combining formula (1) to formula (6), the inductance can be deduced as

$$
\begin{aligned}
& L \approx \frac{U T_{\mathrm{S}}}{\Delta i_{\mathrm{Lt}}} \mathrm{D}_{14}=\frac{4 \times 0.0001}{3} \times 0.66 \approx 88 \mu \mathrm{H} \\
& L_{m} \approx \frac{U T_{\mathrm{S}}}{\Delta i_{\mathrm{L}+}} \mathrm{D}_{14}=\frac{4 \times 0.0001}{6} \times 0.66 \approx 44 \mu \mathrm{H}
\end{aligned}
$$

The actual value of $L$ and $L_{\mathrm{m}}$ is defined as $100 \mu \mathrm{H}$ and $50 \mu \mathrm{H}$, respectively. The other parameters are defined as shown in TABLE II.

\section{MODELING AND SIMULATION}

\section{A. Modeling of lithium-ion battery}

The equivalent circuit model is the most widely used as power battery electric model [20-21]. The voltage source is used to represent the thermodynamic equilibrium potential of the battery and the $R C$ network is used to describe the dynamic characteristics. Applying this kind of model, the parameter identification test is easy to perform, which makes it easier to consider temperature effects in the model.

Steady state changes of battery open circuit voltage can be described as follow:

$$
U_{\mathrm{OC}}=f(\mathrm{SOC}, T)
$$

Combining the above equation model with the first-order RC model, namely Thevenin model [22], to establish a battery model, which is shown in Fig. 8.

The open-circuit voltage (OCV) -SOC test under different temperatures was conducted in our work and the experimental results partly shown in Fig. 9. The results were used to get the concrete expression of equation (9) by way of polynomial fitting, whose result is shown in Fig. 10. Hence, the equation (9) can be restated as follow: 


$$
\begin{aligned}
O C V= & 3.276-0.0022 \cdot T+5.727 \cdot S O C+0.0178 \cdot T \cdot S O C \\
& -24.7 \cdot S O C^{2}-0.0581 \cdot T \cdot S O C^{2}+48.9 \cdot S^{3} C^{3} \\
& +0.0774 \cdot T \cdot S O C^{3}-43.99 \cdot S^{4} C^{4} \\
& -0.0349 \cdot T \cdot S O C^{4}+14.88 \cdot S^{5} C^{5}
\end{aligned}
$$

Hybrid Power Pulse Characteristic (HPPC) test is used to test the pulse capability of batteries under different depths of discharge (DOD) in different time durations. It can be used for parameter identification of the battery model. Part of the HPPC test results under different temperatures is shown in Fig. 11. Genetic algorithm (GA) is applied [23], based on the test results, to implement the parameter identification. The Genetic Algorithm Toolbox in MATLAB is utilized for the identification. An appropriate objective function and the corresponding fitness function ought to be written in the form of $\mathrm{m}$ file to achieve the iterative algorithm while the test data are imported using global variables. Finally, the identification result is shown in Fig. 12. On the basis of the result of the genetic algorithm, the optimal individual is worked out so that the parameters of the $R C$ network can be calculated, shown in TABLE III.

In summary, the precise model of the lithium-ion battery is fully established, prepared for the modeling and simulation in MATLAB and Simulink.

\section{B. Modeling of SOC Estimation Algorithm}

Different from the estimation of the SOC in a simple charging and discharging process, the equalizing current causes the currents on the respective cells of the seriesconnected battery pack to be different in the equalization process. In practical applications, it is impossible to add one current sensor on each branch. Hence, there is no way to directly measure the current value of each battery cell.

In this regard, based on the measurement of the voltage value of each cell, the calculation of the current value can be applied by means of ampere-hour measurement method to estimate the SOC of each cell. Meanwhile, the observed voltage and temperature values are utilized to infer the SOC, used as the observations in the extended Kalman filter (EKF) algorithm, which is used to correct the SOC calculated by the ampere-hour measurement method [24-25].

The MATLAB-Function modules are used to build both the current calculation and SOC estimation models. The iteration operation of the EKF algorithm depends on the Unit Delay module in Simulink library. Fig. 13 shows the convergence of the SOC estimation value obtained by the EKF algorithm for a given SOC value with different initial values. It can be found that the error of the initial value affects the convergence speed though, after a certain number of iterations, the initial error can be eliminated, which supports the feasibility of this algorithm.

\section{Simulation of equalization}

In order to verify the effectiveness of the proposed topology, a model is constructed in MATLAB software, shown in Fig. 14. Combining the contents of part A and part B in this

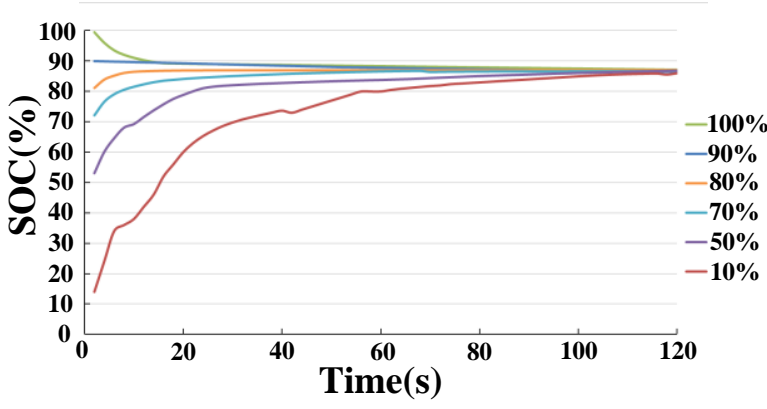

Fig.13 SOC estimation results of EKF with different initial values.

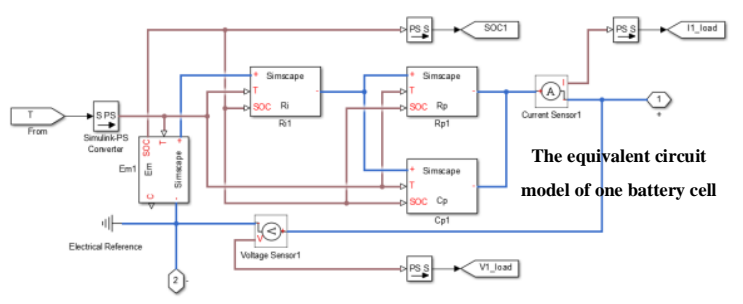

(a)

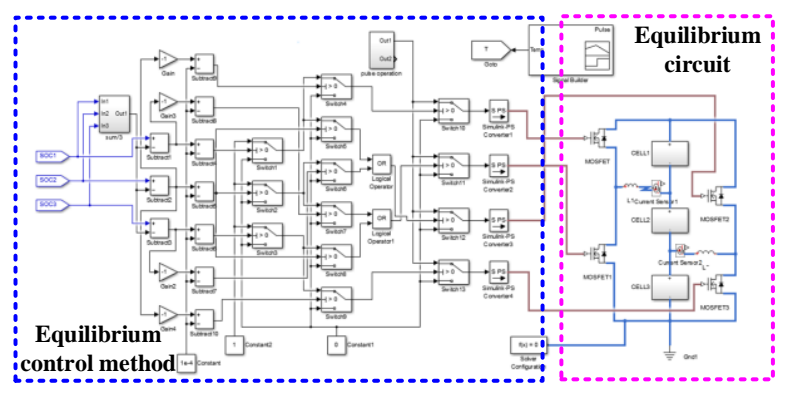

(b)

Fig.14 The simulation model in MATLAB-Simulink. (a) The equivalent circuit model of one battery cell; (b) The equalization model.

section, the battery pack, the SOC estimation algorithm, equalization circuit and its control module can be modeled respectively and work collaboratively, based on the Simscape module, which can realize the modeling of multiple physical domains system [26].

The most important feature of the proposed equalization topology, compared with the traditional one, lies in the structure of the equalization unit, which is composed of three battery cells. Therefore, the working characteristics of this equalization unit should be paid more attention in this simulation.

Fig. 15 shows the typical simulation results of the equalization process under the standing condition. When the maximum difference of SOC is less than one percent, it can be considered as equalized. When the maximum difference of the initial SOC value is less than five percent, the equalization can be implemented in less than 400 seconds and the different initial SOC of the cells will not cause changes in the equalization speed. In contrast, if the traditional Buck-Boost 


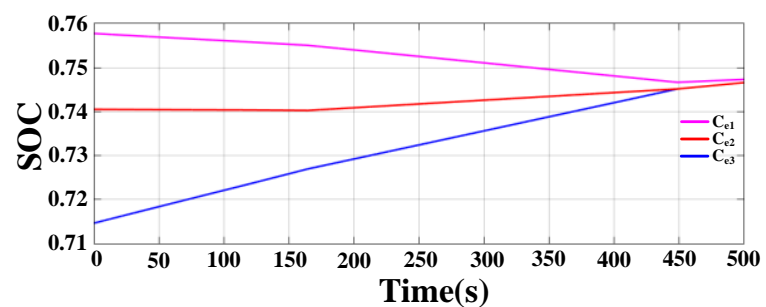

(a)

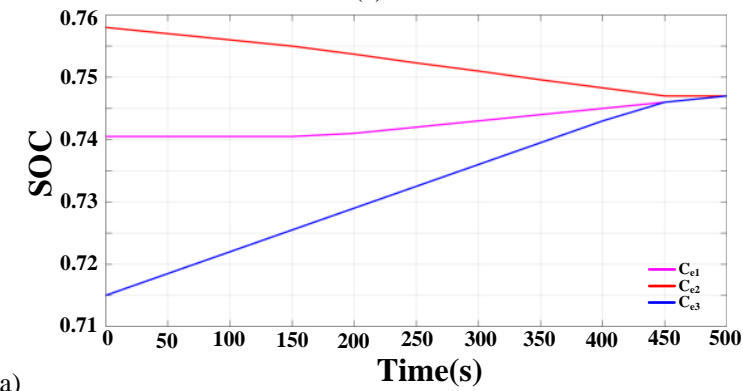

(b)

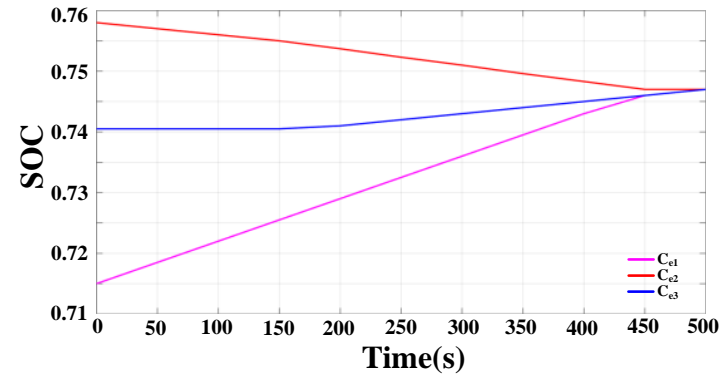

(c)

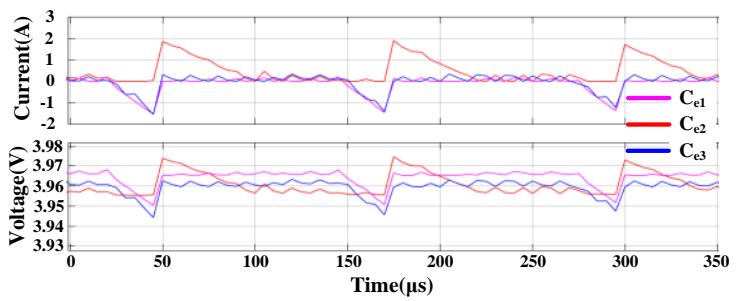

(d)

Fig.15 Simulation results of the proposed equalization process under the standing condition.(a) The change of SOC $\left(\mathrm{Ce}_{1}>\mathrm{Ce}_{2}>\mathrm{Ce}_{3}\right)$; (b) The change of SOC $\left(\mathrm{Ce}_{2}>\mathrm{Ce}_{1}>\mathrm{Ce}_{3}\right)$; (c) The change of SOC $\left(\mathrm{Ce}_{2}>\mathrm{Ce}_{3}>\mathrm{Ce}_{1}\right)$; (d)The current and voltage of cells $\left(\mathrm{Ce}_{1}>\mathrm{Ce}_{2}>\mathrm{Ce}_{3}\right)$

topology is used for equalization, the balancing time spent within the same current limit is typically around 600 seconds as shown in Fig.16. The equalization process under the charging and discharging condition is shown in Fig.17 and Fig.18. Meanwhile, the status of battery charge and discharge during the Urban Dynamometer Driving Schedule (UDDS) cycle were introduced into the simulation of two equalization circuits for dynamic performance comparison, and the extreme difference of SOC of two equalization methods were shown in Fig.19. The results show that the two-stage equilibrium topology proposed in this paper can perform faster battery balancing with fewer devices during the operation of electric vehicles.

Demonstrated by the simulation results above, the most

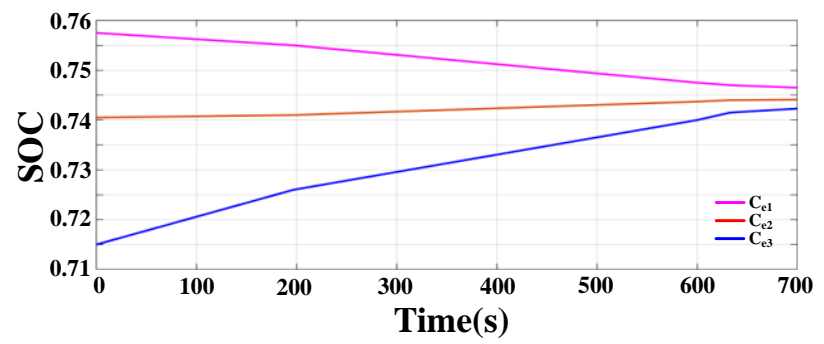

Fig.16 Simulation results of traditional two-stage equalization circuit.

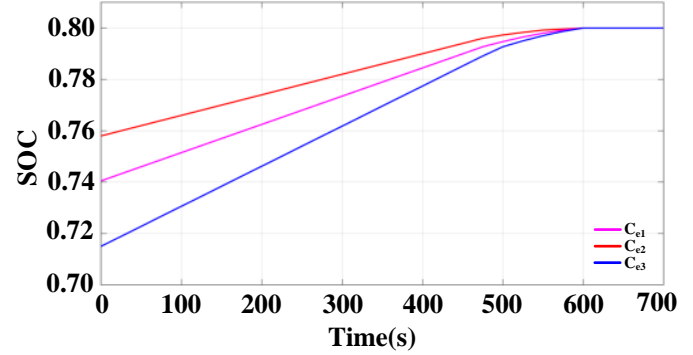

(a)

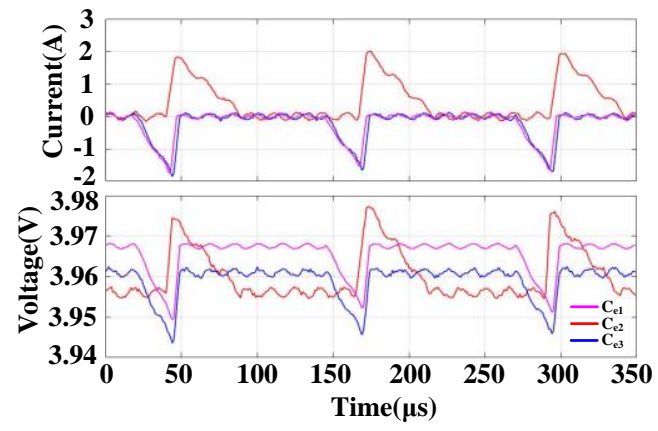

(b)

Fig.17 Simulation results of the proposed equalization process under the charging condition.(a) The change of SOC; (b)The current and voltage of cells

important advantage of the proposed topology is that the equalization unit, composed of three batteries, can achieve equalization costing less time. Because whatever the initial condition, the cell with the largest SOC value can transfer energy directly to the lowest one, benefitting from the establishment of direct contact of every two cells by the proposed topology structure.

\section{Efficiency analysis}

Actually, the realization of active equalization strategy is to reallocate the energy among cells through the energy storage components such as inductances. Since the actual inductance and the devices have equivalent series resistances, it is inevitable that the energy will be lost in the transfer process.

The proposed topology in this paper takes three cells as a battery pack, which is different from the traditional topology, as shown in Fig. 1 and Fig.3. The analysis of efficiency is based on three cells.

The energy can only be transferred between adjacent two batteries in traditional circuit topology shown in Fig.1. If the battery capacity appears as shown in Fig.15(a), the energy 


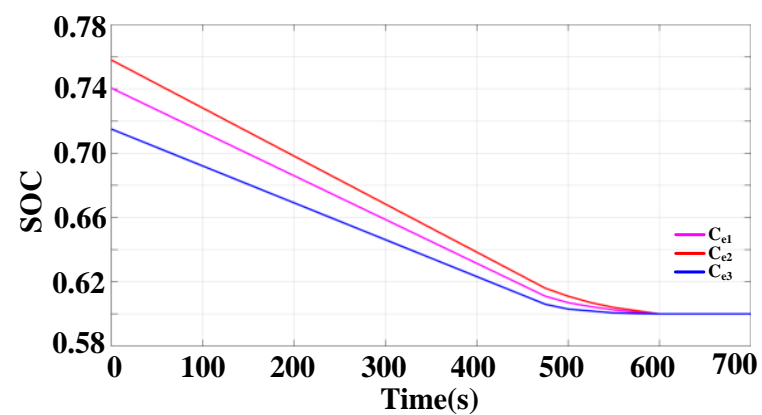

(a)

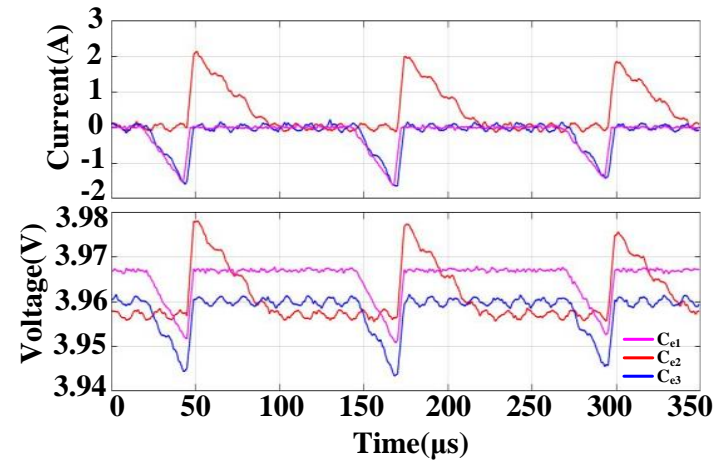

(b)

Fig.18 Simulation results of the proposed equalization process under the discharging condition.(a) The change of SOC; (b)The current and voltage of cells

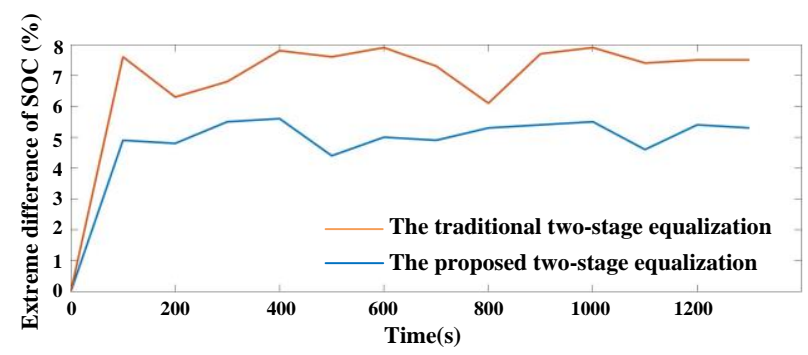

Fig.19 Comparison of two equalization methods under UDDS

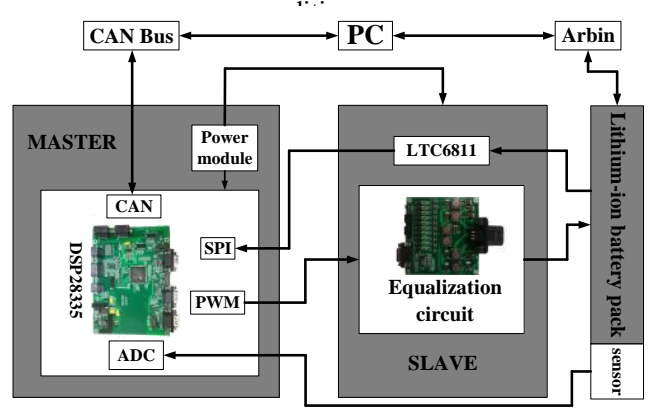

Fig.20 Equalization system block diagram

from $C_{1}$ can only be transmitted to $C_{3}$ through $C_{2}$. This transmission path contains two inductors. If the new topology is adopted, the energy will be transferred directly from $\mathrm{C}_{1}$ to $\mathrm{C}_{3}$. In this way, unnecessary power transmission path can be avoided, which can not only shorten the equilibrium time, but also reduce the transmission loss.

The power losses in equilibrium process are composed of the following two parts.
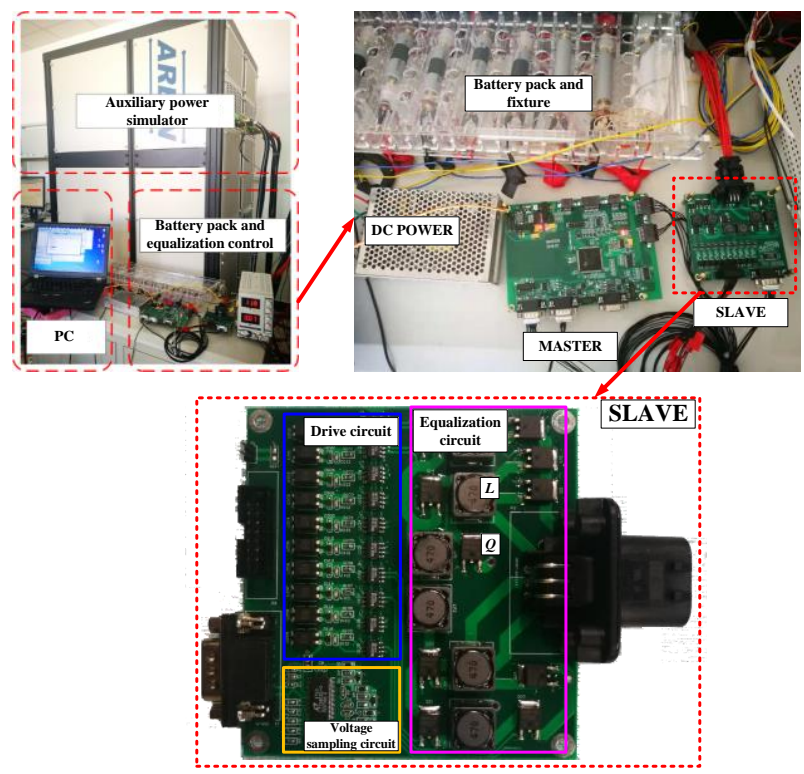

Fig.21 Experimental platform diagram

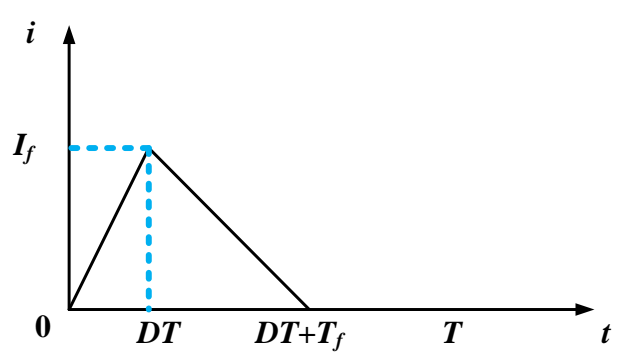

Fig.22 The inductive current in the process of equalization

When the battery charges the inductor, the loss of the circuit is expressed as follows:

$$
P_{\text {loss_charge }}=I_{u}^{2}\left(R_{M}+R_{L}\right)
$$

where $I_{\mathrm{u}}$ is the average current charging the inductance; $R_{\mathrm{M}}$ is the conduction resistance of MOSFET; $R_{\mathrm{L}}$ is the equivalent series resistance of inductance.

When the inductance is charging the battery, the MOSFET in the circuit is closed. According to the characteristics of MOSFET, the reverse current can only flow through the reverse parallel diode, in this case, the circuit loss energy is expressed as:

$$
P_{\text {loss_discharge }}=I_{d}^{2}\left(R_{D}+R_{L}\right)
$$

where $I_{\mathrm{d}}$ is the average current charging the battery; $R_{\mathrm{D}}$ is the conduction resistance of diode. The current path of the cell during charging and discharging are shown in Fig.6c.

Since the switching frequency is much higher than the change frequency of SOC, the inductance current of the buckboost circuit can be assumed as linear change when the switching device changes in one cycle, as shown in Fig. 22.

When the battery charges the inductor, the inductance current is: 


$$
i_{L 1}=\frac{V_{1} t}{L}(0<t<D T)
$$

where $i_{\mathrm{L} 1}$ is the current flowing through the inductance; $V_{1}$ is the battery voltage; $L$ is the value of inductance; $D$ is the duty; $T$ is one cycle time.

At $D T$, the current reaches its maximum:

$$
I_{p}=\frac{V_{1} D T}{L}
$$

From 0 to $D T$, the current increases from 0 to $I_{\mathrm{p}}$, the average current of the battery charging the inductance is

$$
I_{u}=\frac{1}{T} \int_{0}^{D T} \frac{V_{1} t}{L} d t=\frac{V_{1} D^{2} T}{2 L}
$$

From $D T$ to $D T+T_{\mathrm{f}}$, the inductance is discharged, the current drops to 0 , and there is

$$
i_{L 2}=-\frac{I_{p}}{T_{f}} t+I_{p}+\frac{D T I_{p}}{T_{f}}\left(D T<t<D T+T_{f}\right)
$$

The average current of the inductance charging the battery over a period of time is

$$
I_{d}=\frac{1}{T} \int_{D T}^{D T+T_{f}}-\frac{I_{p}}{T_{f}} t+I_{p}+\frac{D T I_{p}}{T_{f}} d t=\frac{V_{1} D T_{f}}{2 L}
$$

For the case shown in Fig.15(a), adopting a traditional topology, the energy from the $C_{1}$ can only be transmitted to $C_{3}$ through $C_{2}$. This path contains two inductors. The losses are:

$$
P_{\text {loss_ } 1}=2\left(P_{\text {loss_charge }_{-}}+P_{\text {loss_discharge }}\right)
$$

The circuit efficiency is:

$$
\eta_{1}=\frac{P_{i n}-P_{l o s s_{-} 1}}{P_{i n}}
$$

Adopting the new topology, the energy can be transferred directly from $\mathrm{C}_{1}$ to $\mathrm{C}_{3}$. The losses are:

$$
P_{\text {loss_2 }}=P_{\text {loss_charge }}+P_{\text {loss_disch } \arg e}
$$

The circuit efficiency is:

$$
\eta_{2}=\frac{P_{i n}-P_{\text {loss_2 }}}{P_{i n}}
$$

In this paper, the battery voltage $\mathrm{V}_{1}=3.7 \mathrm{~V}, \mathrm{I}_{\mathrm{u}}=\mathrm{I}_{\mathrm{d}}=1.65 \mathrm{~A}$, $\mathrm{R}_{\mathrm{L}}=10 \mathrm{~m} \Omega, \mathrm{R}_{\mathrm{M}}=7.9 \mathrm{~m} \Omega$, and $\mathrm{R}_{\mathrm{D}}=26 \mathrm{~m} \Omega$. Thus, we can obtain: Input power:

$$
P_{\text {in }}=3.7 \times 1.65=6.105 \mathrm{~W}
$$

The losses when the cell charges the inductance:

$$
\begin{aligned}
& P_{\text {loss_charge }}=I_{u}{ }^{2}\left(R_{M}+R_{L}\right) \\
& =1.65^{2} \times(7.9+10) \times 10^{-3}=0.049 \mathrm{~W}
\end{aligned}
$$

The losses when the inductor charges the cell:

$$
\begin{aligned}
& P_{\text {loss_discharge }}=I_{d}{ }^{2}\left(R_{D}+R_{L}\right) \\
& =1.65^{2} \times(26+10) \times 10^{-3}=0.098 \mathrm{~W}
\end{aligned}
$$

The losses and efficiency of a traditional structure are:

$$
P_{\text {loss_1 }}=0.294 W, \eta_{1}=95.2 \%
$$

The losses and efficiency of the new topology are:

$$
P_{\text {loss_2 }}=0.147 \mathrm{~W}, \eta_{2}=97.6 \%
$$

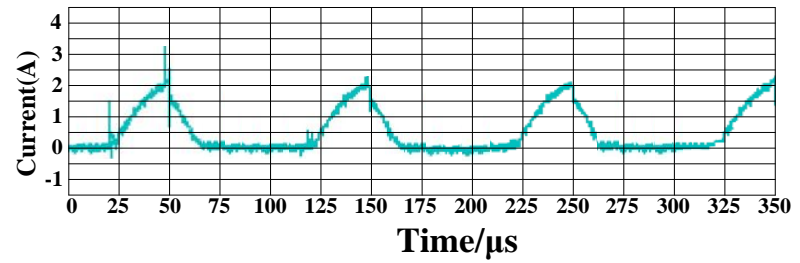

(a)

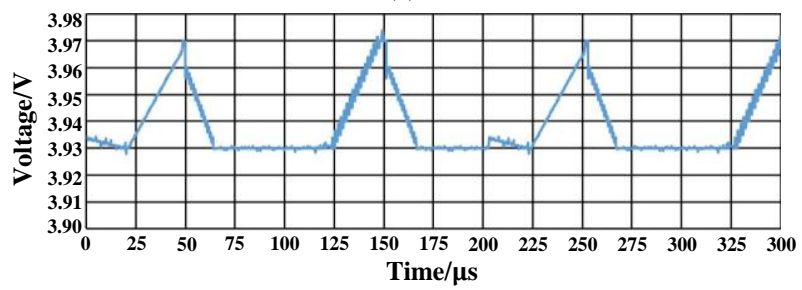

(b)

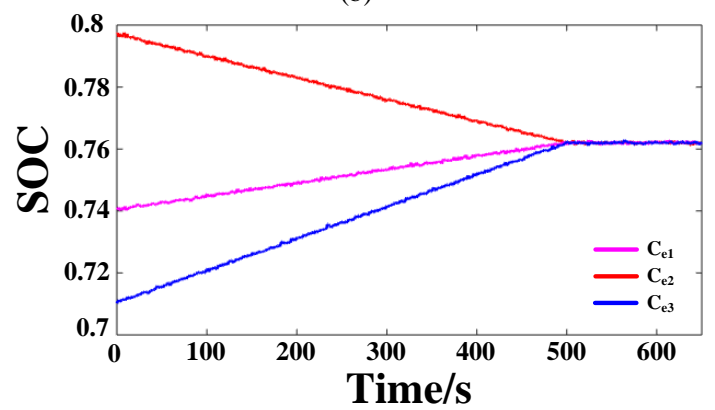

(c)

Fig.23 Experimental results under three batteries:(a) Current of balanced inductor; (b) Voltage of balanced inductor ;(c) The change of SOC

The initial charge of each cell is uncertain, which leads to an uncertainty in the path of power transmission. Although the derivation of equilibrium efficiency is only for the case shown in Fig.15(a), we know that the new topology can reduce unnecessary power transmission paths. Therefore, the new topology proposed in this paper has the higher efficiency.

\section{EXPERIMENT AND RESULTS}

In order to further verify the proposed topology, a prototype was designed and manufactured. The block diagram of the battery equalization system is shown in Fig.20, which is mainly composed of a MASTER controller and a SLAVE controller (acquisition equalization circuit). The MASTER controller includes a power module and a main control chip DSP28335, and the SLAVE controller is composed of an acquisition module, a signal conditioning circuit and an equalization circuit.

Based on the above hardware block diagram, this paper completes the construction of the battery pack active equalization experimental platform, as shown in Fig.21, and the active equalization experiment is carried out on the threecell series battery. Taking into account the switching frequency of $10 \mathrm{kHz}$ and the maximum current of $6 \mathrm{~A}$, the MOSFET is selected by Infineon's power device 


\section{IPD50N04S4.}

In order to simplify the heat dissipation design of the board, the components with small internal resistance are selected and sufficient power margin is left. The PCB board adopts materials with high temperature resistance and high thermal conductivity, and the power devices are evenly distributed in the layout to avoid the concentration of heat on the PCB.

Considering that the switching frequency of the MOSFET in the proposed equalization topology is only $10 \mathrm{kHz}$ and the current level is not high, in order to meet the requirements of electromagnetic compatibility, the master board and the slave board are all integrated with copper in the PCB layout, and a common mode choke is connected in series at the battery connection.

As shown in Fig.23, the battery pack can be effectively balanced by the proposed active equalization topology. And the experimental data was in accordance with the simulation results.

\section{CONCLUSIONS}

This paper proposes a novel non-dissipative two-stage equalization circuit topology based on the traditional BuckBoost converter circuit, to achieve highly efficient balancing of lithium-ion battery packs without adding additional devices. The proposed topology is validated by simulation in MATLAB-Simulink firstly, based on accurate modeling of the lithium-ion battery and apposite application of SOC estimation algorithm. Furthermore, the prototype of the new topology was designed and manufactured. From both the simulation and experiment results, it could conclude that the balancing speed is high due to the structural advantages of the proposed topology.

\section{ACKNOWLEDGEMENT}

This work was supported in part by the National Natural Science Foundation of China under Project 51877006 and in part by the Aeronautical Science Foundation of China 20162851016.

\section{REFERENCES}

[1] Ding X.F., Du M., Duan C.W., Guo H., et al., Analytical and Experimental Evaluation of SiC-Inverter Nonlinearities for Traction Drives Used in Electric Vehicles, IEEE Transactions on Vehicular Technology, vol. 67, no. 1, pp: 146-159, Jan. 2018.

[2] H. Rahimi-Eichi, U. Ojha, F. Baronti and M. Chow. "Battery management system: an overview of its application in the smart grid and electric vehicles," IEEE Trans. Ind. Electron M, vol.7, no.4, pp.4-16, Jun.2013.

[3] Gallardo-Lozano J, Romero-Cadaval E, Milanes-Montero M I, et al. Battery equalization active methods. Journal of Power Sources, 2014, 246(3):934-949.

[4] Momayyezan M, Hredzak B, Agelidis V. A Load-Sharing Strategy for the State of Charge Balancing Between the Battery Modules of Integrated Reconfigurable Converter. IEEE Transactions on Power Electronics, 2017, PP(99):1-1.

[5] Eghtedarpour, N.; Farjah, E., "Distributed charge/discharge control of energy storages in a renewable-energy-based DC micro-grid," Renewable Power Generation, IET, vol.8, no.1,pp.45,57, January 2014

[6] Ling R, Wang L, Huang X, et al. A review of equalization topologies for lithium-ion battery packs// Control Conference. IEEE, 2015:7922-7927.

[7] Teofilo, V.L.; Merritt, L.V.; Hollandsworth, R.P., "Advanced lithium ion battery charger," Battery Conference on Applications and Advances, 1997, Twelfth Annual, vol., no., pp.227,231, 1417 Jan 1997.

[8] Lee, Yuang-Shung; Guo-Tian Cheng, "Quasi-Resonant ZeroCurrent-Switching Bidirectional Converter for Battery Equalization Applications," Power Electronics, IEEE Transactions on, vol.21, no.5, pp.1213,1224, Sept. 2006.

[9] Phung T H, Collet A, Crebier J C. An Optimized Topology for Next-to-Next Balancing of Series-Connected Lithium-ion Cells[J]. IEEE Transactions on Power Electronics, 2011, 29(9):4603-4613.

[10] Rui Ling; Qiang Dan; Lizhi Wang, "Energy Bus-based Equalization Scheme with Bidirectional Isolated Cuk Equalizer for Series Connected Battery Strings" Applied Power Electronics Conference and Exposition (APEC), 2015 30th IEEE, 15-19 March. 2015.

[11] Nguyen N, Oruganti S K, Na K, et al. An Adaptive Backward Control Battery Equalization System for Serially Connected Lithium-ion Battery Packs[J]. IEEE Transactions on Vehicular Technology, 2014, 63(8):3651-3660.

[12] Chen Y, Liu X, Cui Y, et al. A MultiWinding Transformer Cellto-Cell Active Equalization Method for Lithium-Ion Batteries With Reduced Number of Driving Circuits[J]. IEEE Transactions on Power Electronics, 2016, 31(7):4916-4929.

[13] Gottwald, T.; Ye, Z.; Stuart, T., "Equalization of EV and HEV batteries with a ramp converter," Aerospace and Electronic Systems, IEEE Transactions on, vol.33, no.1, pp.307,312, Jan. 1997.

[14] Ling R, Dan Q, Zhang J, et al. A distributed equalization control approach for series connected battery strings[M]. 2014.

[15] Phung T H, Collet A, Crebier J C. An Optimized Topology for Next-to-Next Balancing of Series-Connected Lithium-ion Cells. IEEE Transactions on Power Electronics, 2011, 29(9):4603-4613.

[16] Yu Liu, Chaoying Xia, Miao Gu, et al. A novel active equalizer for Li-ion battery pack in electric vehicles[J]. Applied Energy, 2019, vol.158, pp.2649-2654.

[17] Peng F, Wang H, Yu L . Analysis and Design Considerations of Efficiency Enhanced Hierarchical Battery Equalizer Based on Bipolar CCM Buck-Boost Units[J]. IEEE Transactions on Industry Applications,2019, 55(4), PP(99):1-1.

[18] X. Ding and D. Zhang, "A Novel Active Equalization Topology for Series-Connected Lithium-ion Battery Packs," in Proc. 2018 IEEE Energy Conversion Congress and Expo. (ECCE), Portland, OR, USA, pp. 2753-2758.

[19] Moo C S, Yao C H, Tsai I S. Charge equalization for seriesconnected batteries. Aerospace \& Electronic Systems IEEE Transactions on, 2003, 39(2):704-710.

[20] N. Lin, S. Ci, and H. Li.An enhanced circuit-based battery model with considerations of temperature effect. Energy Conversion Congress and Exposition, 2014 IEEE, 2014, pp. 3985-3989.

[21] Ding X.F., Zhang D.H., Cheng J.W., Wang B.B., Luk P.C., An improved Thevenin model of lithium-ion battery with high accuracy for electric vehicles, Applied Energy, Volume 254, 2019.

[22] Xiong R, He H, Guo H, et al. Modeling for Lithium-Ion Battery used in Electric Vehicles. Procedia Engineering, 2011, 15(1):2869-2874.

[23] Goldberg D E. Genetic Algorithm in Search Optimization and Machine Learning. Addison Wesley, 1989, xiii(7):2104-2116.

[24] Li W., Liang L., Liu W., Wu X., State of Charge Estimation of Lithium Ion Batteries Using a Discrete Time Nonlinear Observer," IEEE Transactions on Industrial Electronics, vol. 64, no.11, pp.8557-8565, 2017.

[25] Charkhgard M, Farrokhi M. State-of-Charge Estimation for Lithium-Ion Batteries Using Neural Networks and EKF. IEEE Transactions on Industrial Electronics, 2010, 57(12):4178-4187. 


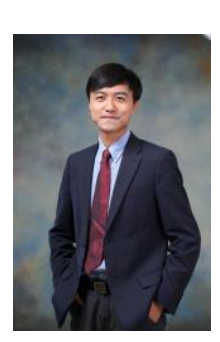

[26] Jain A, Cameron J, Lim C, et al. SIMSCAPE Terrain Modeling Toolkit. IEEE Computer Society, 2006.

Xiaofeng Ding received the B.S., M.S., and Ph.D. degrees in electrical engineering from Northwestern Polytechnical University, Xian, China, in 2005, 2008, and 2011, respectively. From 2008 to 2010, he was a Visiting Scholar with the University of MichiganDearborn, Dearborn, MI, USA.

$\mathrm{He}$ is currently an Associate Professor with the Department of Electrical Engineering, Beihang University, Beijing, China. His research interests include permanent magnet machines, motor drives, and silicon carbide devices.

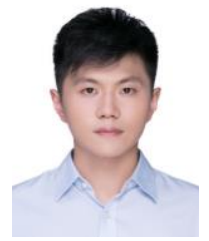

Donghuai Zhang received the B.S. and M.S. degrees in electrical engineering from the School of Automation Science and Electrical Engineering, Beihang University, Beijing, China, in 2016 and 2019.

His research interest includes battery management and motor driver.

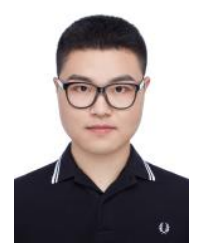

Jaiwei Cheng received the B.S. degree in electrical engineering from China University of Mining and Technology, Beijing, China, in 2017, and the M.S. degree in electrical engineering from the School of Automation Science and Electrical Engineering, Beihang University, Beijing, China, in 2020.

His research interests include permanent magnet electric machines drivers based on wide bandgap power devices such as silicon carbide.

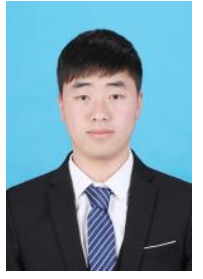

Binbin Wang received the B.S. degree in electrical engineering from the School of Automation Science and Electrical Engineering, Beihang University, Beijing, China, in 2020. He is currently working toward the M.S. degree in electrical engineering from the School of Automation Science and Electrical Engineering, Beihang University, Beijing, China.

His research interests include permanent magnet electric machines drivers and Reliability prediction of power devices.

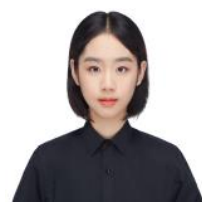

Yameng Chai received the B.S. degree in electrical engineering from the School of Automation Science and Electrical Engineering, Beihang University, Beijing, China, in 2020. She is currently working toward the M.S. degree in electrical engineering from the School of Automation Science and Electrical Engineering, Beihang University, Beijing, China.

Her research interests include permanent magnet electric machines and drivers.

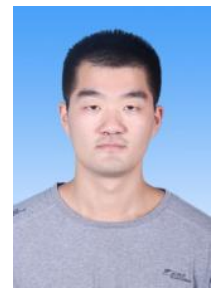

Zhihui Zhao received the B.S. degree in automation from the School of the Automation in Qingdao University, Qingdao, China, in 2019. He is currently working toward the M.S. degree in electrical engineering from the School of Automation Science and Electrical Engineering, Beihang University,

Beijing, China.

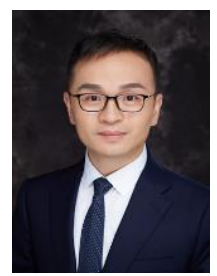

His research interest includes motor drive and control.

Rui Xiong received the M.Sc. degree in vehicle engineering and the Ph.D. degree in mechanical engineering from the Beijing Institute of Technology, Beijing, China, in 2010 and 2014, respectively. From 2012 to 2014, he conducted scientific research as a Joint Ph.D. Student at the University of Michigan, Dearborn, MI, USA.

He is currently a Professor with the Department of Vehicle Engineering, School of Mechanical Engineering, Beijing Institute of Technology. His research interests include electrical/hybrid vehicles, energy storage, and battery management.

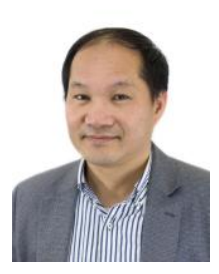

Partrick Chi Kwong Luk received the High Diploma with merits (B.Sc.) in electrical engineering from Hong Kong Polytechnic University, Hung Hom, Kowloon, Hong Kong, in 1983, the M.Phil. degree in electrical engineering from Sheffield University, Sheffield, U.K., in 1989, and the Ph.D. degree in electrical engineering from the University of South Wales, Pontypridd, U.K., in 1992. In 2002, he joined Cranfield University, Bedford, U.K., where he is a Chair Professor in electrical engineering.

His current research interests include electrical drives, renewable energy systems, and high-frequency power electronics. 